\title{
Repeatability and Reproducibility Standard Deviations in the Measurement of Trace Moisture Generated Using Permeation Tubes
}

\section{Peter H. Huang and Raghu Kacker}

National Institute of Standards and Technology,

Gaithersburg, MD 20899-0001, U.S.A.

peter.huang@nist.gov raghu.kacker@.nist.gov

\author{
Permeation-tube moisture generators are \\ used in industry as calibrated sources of \\ water vapor and carrier gas mixtures. \\ Measurements were made using three \\ permeation-tube moisture generators of the \\ type used in the semiconductor industry. \\ This paper describes repeatability and \\ reproducibility standard deviations in \\ measurement of moisture concentration \\ from such generators. Repeatability refers \\ to measurements within a system and \\ reproducibility refers to measurements \\ between systems. Two independent \\ methods were used to measure the realized \\ concentration of water vapor. The first \\ measurement, the calculated value, was \\ determined using calibrated permeation \\ rate of permeation-tube and flow rate of \\ dry carrier gas. This is the industrial \\ method of evaluating moisture concentra- \\ tion. The second measurement, the \\ measured value, was determined using the \\ low frost-point generator at the National \\ Institute of Standards and Technology \\ (NIST) and a quartz-crystal-micro-balance. \\ Four pairs of independent measurements
}

\begin{abstract}
for each generator and for six nominal levels in the range from $10 \mathrm{~nL} / \mathrm{L}$ to $100 \mathrm{~nL} / \mathrm{L}$ were made. The characteristic used to quantify repeatability and reproducibility standard deviations in industrial measurements is the calculated value minus the measured value. Repeatability standard deviation ranges from $1 \mathrm{~nL} / \mathrm{L}$ to $2 \mathrm{~nL} / \mathrm{L}$, approximately. Reproducibility standard deviation ranges from $2 \mathrm{~nL} / \mathrm{L}$ to $8 \mathrm{~nL} / \mathrm{L}$, approximately. The documentary ASTM standard E691-99 was used for both data validation and quantification of the repeatability and reproducibility standard deviations.
\end{abstract}

Keywords: humidity standard; interlaboratory evaluations; measurement uncertainty; permeation-tube; repeatability; reproducibility; trace moisture measurement.

Accepted: March 24, 2003

Available online: http://www.nist.gov/jres

\section{Introduction}

Permeation-tube moisture generators (PTMGs) were used to produce water vapor in a stream of pure nitrogen carrier gas. A PTMG produces a stable flow of water vapor permeating through a membrane-tube containing liquid water at a constant temperature and pressure. The water vapor is mixed with a metered stream of dry carrier gas. The concentration of moisture is calculated using the permeation rate of water vapor and the flow rate of dilution gas as discussed in Ref. [1]. This type of apparatus is commonly used in the semiconductor industry as a portable standard for the calibration of hygrometers.

Another apparatus for producing low levels of moisture in a stream of carrier gas is the low frost-point generator (LFPG) at the National Institute of Standards and Technology (NIST), which is based on thermodynamic 
principles. Compressed gas is purified and passed through a long-coiled saturator that is controlled at a stable temperature. The gas leaves the saturator completely saturated with water vapor in equilibrium at an absolute pressure and temperature. Measurements of the pressure and temperature within the saturator, along with the known relationship between the equilibrium water vapor pressure and the temperature of the ice in the saturator are used to determine the water vapor concentration. Additional details are given in Ref. [2].

The object of this study is to quantify the variation in measurement of water vapor generated by PTMGs used in industry. Two types of variation are of interest: variation within a system and variation between systems. The Guide to the Expression of Uncertainty in Measurement [3] defines repeatability conditions as the same conditions of measurement over a short period of time and reproducibility conditions as changed conditions of measurement. The change in this study is the use of different PTMG instruments. The terms repeatability standard deviation and reproducibility standard deviation as used here are contractions of "standard deviation in repeatability conditions" and "standard deviation in reproducibility conditions" respectively.

Data on the measurement of moisture content were collected over a period of 2 years for nominal water vapor concentrations of $10 \mathrm{~nL} / \mathrm{L}, 20 \mathrm{~nL} / \mathrm{L}, 40 \mathrm{~nL} / \mathrm{L}$, $60 \mathrm{~nL} / \mathrm{L}, 80 \mathrm{~nL} / \mathrm{L}$, and $100 \mathrm{~nL} / \mathrm{L}$ generated from three PTMGs. This range of concentration is important in the specification of gases such as nitrogen used in the semiconductor industry. The three PTMG instruments are labeled here as A, B, and C. The PTMGs were constructed on the same principle but with different hardware and represent typical PTMGs used in industry. They were loaned to NIST for measurement. The PTMGs were calibrated at the source, thus they represent industrial use conditions. The repeatability measurements for each instrument were made sequentially over a relatively short period of time. The reproducibility measurements using different instruments were made over a relatively long period of time. Thus the reproducibility represented here is a relatively long-term variation.

For each nominal level of moisture concentration, the actual concentration of water vapor produced by the PTMG was determined by two independent measurement methods. The two measurements are referred to here as the calculated value $x_{\mathrm{c}}$ and the measured value $x_{\mathrm{m}}$. The calculated value $x_{\mathrm{c}}$ was determined using the calibrated permeation rate of the permeation-tube and the calibrated flow rate of the dry carrier gas. The measured value $x_{\mathrm{m}}$ of moisture concentration was deter- mined by a standard substitution method using the NIST's low frost-point generator (LFPG) and a quartzcrystal-micro-balance. We made four pairs of independent repeat measurements for each level and each generator.

In industry, the calculated value $x_{\mathrm{c}}$ is used as the amount of water vapor concentration produced by a PTMG. The measurand, quantity subject to measurement, is the actual moisture concentration. Repeatability and reproducibility standard deviations are defined for a fixed value of the measurand. In this application it is not practical to realize a fixed level of moisture. There is always some variation in the actual moisture concentration about the nominal level. So the characteristic used here to quantify repeatability and reproducibility standard deviations in industrial measurements is the difference $\delta x=x_{\mathrm{c}}-x_{\mathrm{m}}$, where $x_{\mathrm{c}}$ and $x_{\mathrm{m}}$ are the calculated and measured values of the same actual moisture concentration determined simultaneously. This is a different scale for quantifying repeatability and reproducibility standard deviations. The measured values from the NIST LFPG are highly repeatable and they are in effect used as reference values to quantify repeatability and reproducibility standard deviations of PTMG measurements.

\section{Statistical Analysis}

The data on the difference $(\delta x)$ of calculated value $x_{\mathrm{c}}$ from measured value $x_{\mathrm{m}}$ are presented in Table 1 and plotted in Fig. 1. The statistical analysis has two objectives. First, the data are investigated to validate their suitability for quantifying repeatability and reproducibility standard deviations. Then repeatability and reproducibility standard deviations are quantified for validated data. We have used the statistical method recommended by ASTM standard E691-99 [4] to investigate the data as well as to quantify repeatability and reproducibility standard deviations. This documentary standard and its previous editions have existed for over 20 years. Despite being very useful, it does not seem to have been widely used. One of our objectives is to show its utility. The statistical analysis is done separately for each level of nominal concentration.

The objectives of the first part of data analysis are as follows. (1) Check for evidence of instrument effects. (2) Check whether within-instrument standard deviations are similar. (3) Check that there are no highly discrepant instrument arithmetic means. The four measurements for a given nominal level and instrument are referred to as a cell. The data is investigated by examining the $k$-statistic and the $h$-statistic for each cell. Formulas for the $k$-statistic and $h$-statistic are 
Table 1. Data on difference in measurement: calculated value minus measured value

\begin{tabular}{|c|c|c|c|c|c|}
\hline $\begin{array}{l}\text { Nominal concentration } \\
(\mathrm{nL} / \mathrm{L})\end{array}$ & $\begin{array}{c}\text { Test } \\
\text { instrument }\end{array}$ & $\begin{array}{l}\text { Test } 1 \\
(\mathrm{~nL} / \mathrm{L})\end{array}$ & $\begin{array}{l}\text { Test } 2 \\
(\mathrm{~nL} / \mathrm{L})\end{array}$ & $\begin{array}{l}\text { Test } 3 \\
(\mathrm{~nL} / \mathrm{L})\end{array}$ & $\begin{array}{l}\text { Test } 4 \\
(\mathrm{~nL} / \mathrm{L})\end{array}$ \\
\hline 10 & B & 0.79 & 0.81 & 0.10 & 0.88 \\
\hline 10 & $\mathrm{C}$ & -3.26 & -2.20 & -2.43 & -0.83 \\
\hline 20 & A & 0.37 & -0.04 & 0.17 & 0.23 \\
\hline 20 & $\mathrm{C}$ & -2.57 & -3.06 & -1.78 & -3.46 \\
\hline 40 & A & 0.57 & 0.45 & -0.34 & 1.39 \\
\hline 40 & B & 0.32 & 0.23 & -0.36 & 0.16 \\
\hline 40 & $\mathrm{C}$ & -3.59 & -3.17 & -3.19 & -3.89 \\
\hline 60 & A & 0.87 & 0.58 & 0.86 & 1.19 \\
\hline 60 & B & 0.41 & 0.64 & 0.94 & -0.49 \\
\hline 60 & $\mathrm{C}$ & -4.89 & -6.50 & -4.74 & -4.76 \\
\hline 80 & B & -2.12 & -0.48 & 1.60 & -0.49 \\
\hline 80 & $\mathrm{C}$ & -7.33 & -8.76 & -6.83 & -6.28 \\
\hline 100 & A & 5.43 & 3.95 & 2.50 & 5.73 \\
\hline 100 & B & -2.44 & 2.33 & -1.37 & 1.44 \\
\hline 100 & $\mathrm{C}$ & -11.91 & -11.50 & -9.93 & -9.89 \\
\hline
\end{tabular}

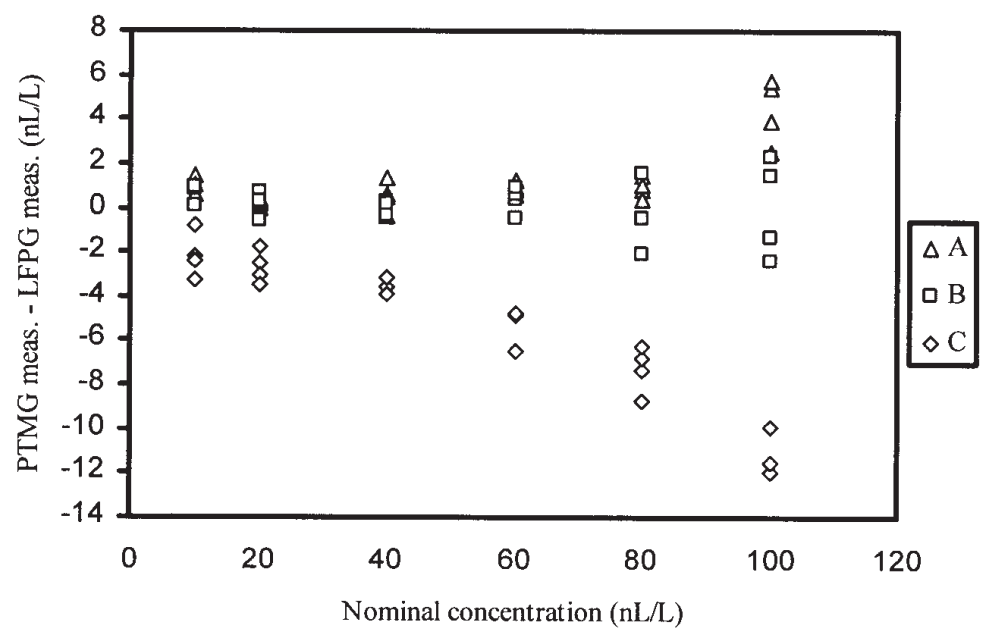

Fig. 1. Difference of Permeation-tube moisture generator (PTMG) measurement called calculated value and the NIST low frost-point generator (LFPG) measurement called measured value. Some data points overlap.

given in Appendix A. The $k$-statistic is normalized within-instrument standard deviation. It is used to check whether within-instrument standard deviations are similar. The $h$-statistic is standardized cell arithmetic mean. It is used to check whether any cell arithmetic means are highly discrepant. Computed values of $k$-statistic and $h$-statistic are presented in Table 2 and charted in Figs. 2 and 3, respectively. The first impres- sion from the chart of $k$-statistic is that the withininstrument standard deviations are different. However, within-instrument standard deviations are based on only four measurements, so we can expect large random fluctuations among them even when there is no instrument or level effect. In view of the small number of measurements, we conclude from the chart of $k$-statistic that within-instrument standard deviations 
Volume 108, Number 3, May-June 2003

Journal of Research of the National Institute of Standards and Technology

Table 2. Table of $k$-statistic and $h$-statistic

\begin{tabular}{cccr}
\hline \hline $\begin{array}{c}\text { Nominal concentration } \\
(\mathrm{nL} / \mathrm{L})\end{array}$ & $\begin{array}{c}\text { Test } \\
\text { instrument }\end{array}$ & $k$-statistic & $h$-statistic \\
\hline 10 & $\mathrm{~A}$ & 0.506 & 0.687 \\
10 & $\mathrm{~B}$ & 0.564 & 0.460 \\
10 & $\mathrm{C}$ & 1.557 & -1.147 \\
20 & $\mathrm{~A}$ & 0.316 & 0.583 \\
20 & $\mathrm{~B}$ & 1.049 & 0.572 \\
20 & $\mathrm{C}$ & 1.341 & -1.155 \\
40 & $\mathrm{~A}$ & 1.451 & 0.673 \\
40 & $\mathrm{~B}$ & 0.626 & 0.476 \\
40 & $\mathrm{C}$ & 0.709 & -1.149 \\
60 & $\mathrm{~A}$ & 0.399 & 0.650 \\
60 & $\mathrm{~B}$ & 0.986 & 0.502 \\
60 & $\mathrm{C}$ & 1.367 & -1.152 \\
80 & $\mathrm{~A}$ & 0.421 & 0.716 \\
80 & $\mathrm{~B}$ & 1.378 & 0.427 \\
80 & $\mathrm{C}$ & 0.961 & -1.143 \\
100 & $\mathrm{~A}$ & 0.888 & 0.836 \\
100 & $\mathrm{~B}$ & 1.349 & 0.272 \\
100 & $\mathrm{C}$ & 0.626 & -1.108 \\
\hline
\end{tabular}

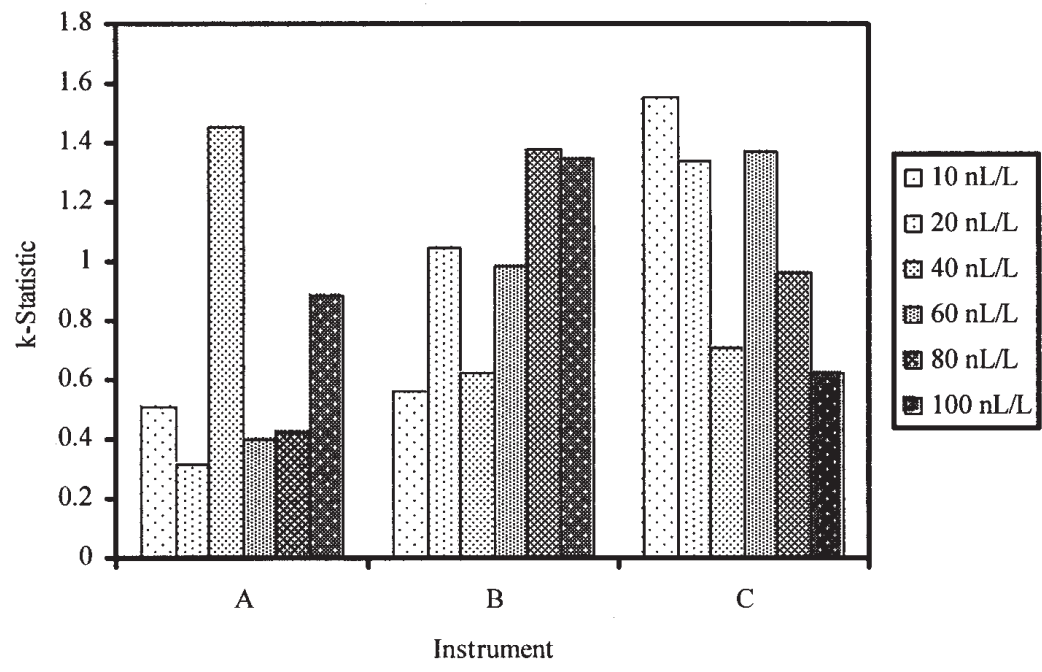

Fig. 2. Chart of $k$-statistic

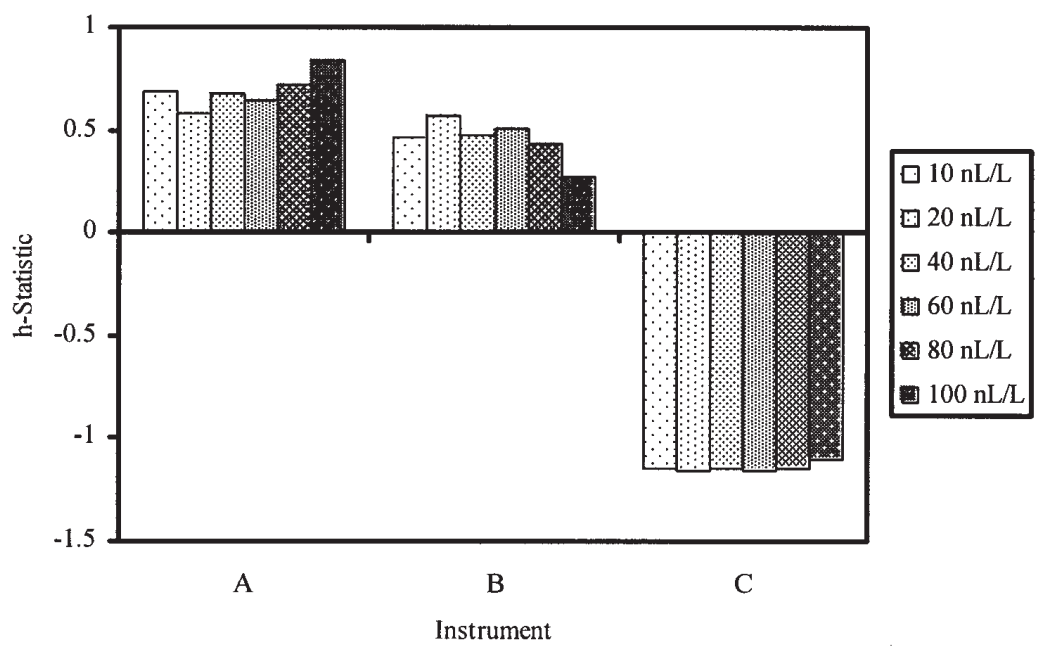

Fig. 3. Chart of $h$-statistic 
are not widely different. This conclusion is supported by the statistical test discussed in Ref. [4], which is applicable when the data can be assumed to have normal distribution. Thus the repeatability standard deviation for a nominal concentration can be computed using all data for that level. The chart of $h$-statistic shows that there is a clear evidence of instrument effects and that there are no highly discrepant instrument arithmetic means. Thus the reproducibility standard deviation for a nominal concentration can be computed using all data for that level. In summary, the data are reasonably valid for quantifying repeatability and reproducibility standard deviations.

Repeatability and reproducibility standard deviations are computed using the formulas given in the ASTM standard E691-99 and reproduced here in the Appendix. The computed values of the repeatability standard deviation, denoted by $s_{\mathrm{r}}$, and the reproducibility standard deviation, denoted by $s_{\mathrm{R}}$, are given in Table 3 and charted in Fig. 4. Since the reproducibility standard deviation includes the repeatability standard deviation, it is always larger. Both the repeatability standard deviation $s_{\mathrm{r}}$ and the reproducibility standard deviation $s_{\mathrm{R}}$ tend to increase with the nominal level. This is to be expected and is consistent with previous findings about the effect of flow-rate [2]. A quadratic polynomial (not shown here) fits well the charts of repeatability standard deviation $s_{\mathrm{r}}$ and reproducibility standard deviation $s_{\mathrm{R}}$ versus the level of nominal concentration. Table 3 also includes arithmetic means of the difference $(\delta x)$ for different nominal concentrations. The arithmetic means are small relative to their reproducibility standard deviations. From Fig. 1, we note that the negative values of the arithmetic mean of the difference $(\delta x)$ are largely caused by data from the PTMG labeled C.

Table 3. Repeatability standard deviation, reproducibility standard deviation, and arithmetic mean of difference in measurement for six levels of nominal concentrations

\begin{tabular}{cccc}
\hline $\begin{array}{c}\text { Nominal } \\
\text { concentration } \\
(\mathrm{nL} / \mathrm{L})\end{array}$ & $\begin{array}{c}\text { Repeatability } \\
s_{\mathrm{r}}(\mathrm{nL} / \mathrm{L})\end{array}$ & $\begin{array}{c}\text { Reproducibility } \\
s_{\mathrm{R}}(\mathrm{nL} / \mathrm{L})\end{array}$ & $\begin{array}{c}\text { Arithmetic } \\
\text { mean } \\
(\mathrm{nL} / \mathrm{L})\end{array}$ \\
\hline 10 & 0.65 & 1.85 & -0.16 \\
20 & 0.54 & 1.73 & -0.79 \\
40 & 0.49 & 2.22 & -0.95 \\
60 & 0.62 & 3.43 & -1.32 \\
80 & 1.11 & 4.52 & -2.26 \\
100 & 1.68 & 7.96 & -2.14 \\
\hline
\end{tabular}

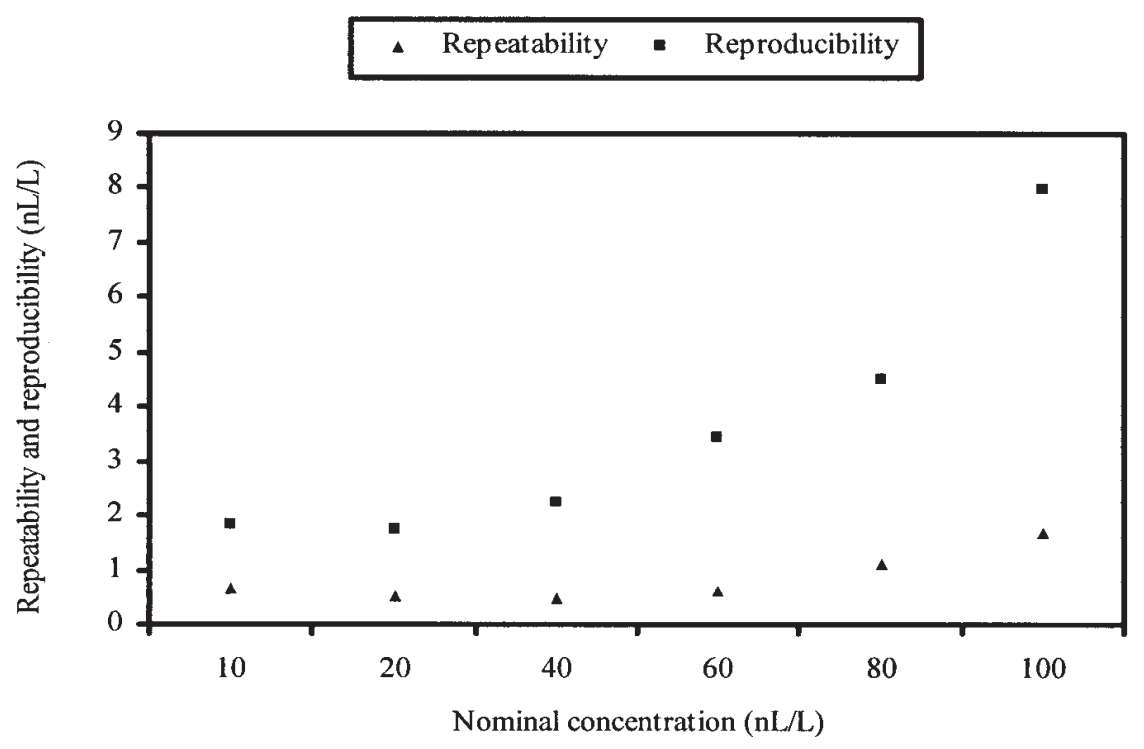

Fig. 4. Chart of repeatability and reproducibility standard deviations. 


\section{Conclusion}

The graphical investigation of data using the $k$-statistic and the $h$-statistic shows that they are reasonable to quantify repeatability and reproducibility standard deviations in PTMG measurements. Thus the repeatability and reproducibility standard deviations given in Table 3 should be of interest to the scientific and technical community. Repeatability standard deviation ranges from $1 \mathrm{~nL} / \mathrm{L}$ to $2 \mathrm{~nL} / \mathrm{L}$, approximately. Reproducibility standard deviation ranges from $2 \mathrm{~nL} / \mathrm{L}$ to $8 \mathrm{~nL} / \mathrm{L}$ approximately. These standard deviations quantify possible variation in measurement of water vapor concentration generated by typical PTMG instruments used in the semiconductor industry.

\section{Appendix A. Formulas}

The following formulas are defined for a fixed level of the nominal moisture concentration. Let $x_{i j}$ denote the $j$-th measurement for the $i$-th apparatus, where $j=1$, $2, \ldots, J$ and $i=1,2, \ldots, I$. Here $J=4$ and $I=3$. Let $x_{i}$ be the arithmetic mean and $s_{i}$ the sample standard deviation of the $J$ measurements. The $k$-statistic is the square-root of normalized variance $s_{i}^{2} /\left(\Sigma_{i} s_{i}^{2} / I\right)$ for $i=1,2, \ldots, I$. It is used to compare the variation of within-instrument standard deviations. Let $x$ be the arithmetic mean and $s$ be the standard deviation of the arithmetic means $x_{1}, \ldots, x_{I}$. The $h$-statistic is the standardized instrument mean $\left(x_{i}-x\right) / s$ for $i=1,2, \ldots, I$. Both the $k$-statistic and $h$-statistic are dimensionless quantities. The repeatability standard deviation is defined as $s_{\mathrm{r}}=\sqrt{\left.\sum_{i} s_{i}^{2} / I\right)}$. This is the denominator of the $k$-statistic. The reproducibility standard deviation is defined as $s_{\mathrm{R}}=\max \left\{s_{r}, \sqrt{\left[s^{2}+(1-1 / J) s_{r}^{2}\right]}\right\}$, Ref. [4].

\section{Acknowledgment}

Dean Ripple and John Sieber provided useful comments and suggestions on an earlier draft. We thank James Whetstone, Geoff McFadden, and Ron Boisvert for their support.

\section{References}

[1] PPM and PPB Humidity Standards, Semiconductor Equipment and Materials International (SEMI) Standard C15 (1995).

[2] P. H. Huang, G. E. Scace, and J. T. Hodges, Referencing Dilution-Based Trace Humidity Generators to Primary Humidity Standards, Proceedings of TEMPMEKO 1, 573-578 (2001).

[3] Guide to the Expression of Uncertainty in Measurement, Second edition, Geneva, International Organization for Standardization (ISO), ISBN 92-67-10188-9 (1995).

[4] Standard Practice for Conducting an Interlaboratory Study to Determine the Precision of a Test Method, ASTM E691 (1999).

About the authors: Peter Huang is a research chemist in the Process Measurements Division of the NIST Chemical Science and Technology Laboratory. Raghu Kacker is a mathematical statistician in the Mathematical and Computational Sciences Division of the NIST Information Technology Laboratory. The National Institute of Standards and Technology is an agency of the Technology Administration, U.S. Department of Commerce. 